\title{
DÍAZ GÓMEZ, José Antonio, El Oratorio de San Felipe Neri de Granada. Historia y patrimonio de una fundación perseguida. Comares, Granada, 2021.
}

\author{
MIGUEL ÁNGEL NIETO MÁRQUEZ \\ Universidad de Sevilla
}

La riqueza patrimonial de la capital granadina siempre acarrea importantes aportaciones científicas en el ámbito de la Historia del Arte. Entre ellas, estas líneas pretenden destacar la labor realizada por José Antonio Díaz Gómez en su último libro, donde se acomete el estudio del Oratorio de San Felipe Neri, así como su efecto en el resto de fundaciones de la mitad sur peninsular. A lo largo de sus 302 páginas, dicho trabajo rescata del olvido a una congregación que desempeñó un papel crucial en las tensiones existentes entre la Corona española y el Papado, poniéndose de manifiesto la relevancia que tuvo desde el siglo XVI hasta el XVIII desde el punto de vista religioso, político y cultural. Por tanto, aunque el estudio de esta institución ha captado el interés de varios investigadores, el autor contribuye notablemente a paliar la escasa atención que ha recibido por parte de la historiografía. Asimismo, teniendo en cuenta la proyección territorial del mencionado instituto, el texto supone un capítulo sustancial para la historia social de nuestro país, sin olvidar la influencia que ejerció su patrimonio mueble e inmueble en otras demarcaciones de la Península.


HISTORIA Y PATRIMONIO
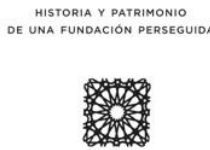

El libro es fruto de las investigaciones realizadas por Díaz Gómez a lo largo de su tesis doctoral, que fue defendida en el Departamento de Historia del Arte de la Universidad de Granada y dirigida por el Dr. Juan Jesús López-Guadalupe Muñoz. Igualmente, la obra está enmarcada en el Proyecto de I+D "Barroco entre dos mundos: relaciones y alternativas de la escultura andaluza e hispanoamericana entre 1700 y 1750" (HAR-2017-83017P) de dicha universidad. Actualmente trabaja como profesor en el Departamento de Historia del Arte de la Universidad de Sevilla, a la que también pertenece el autor del prólogo, el Dr. José Roda Peña, quien subraya el carácter interdisciplinar de la monografía, sus múltiples enfoques metodológicos, su total conocimiento de las fuentes bibliográficas y archivísticas y su acertada redacción y estructuración. 
Tras la introducción, el autor incluye un breve apartado donde se analiza el panorama en el que fueron fundándose los distintos oratorios españoles, clarificando así al lector el destacado papel que tuvo la fundación granadina en todo el proceso. Seguidamente, el grueso de las aportaciones de Díaz Gómez se organiza en tres secciones subdivididas en sus correspondientes epígrafes. La primera sección versa sobre la historia de la congregación en Granada, atendiendo a su controvertida implantación a lo largo del siglo XVII, a su crecimiento y consolidación en el Setecientos, a su dimensión económica, y a su devenir decimonónico. Además, culmina dicho bloque prestando atención a la Orden Tercera de Siervos de Nuestra Señora de los Dolores y al Oratorio sufragáneo de Motril, de breve existencia. En su extensión, se advierte un acertado contraste de la bibliografía con la información localizada en distintos repositorios, de modo que se muestra la gran capacidad del autor para interpretar la documentación.

Lo mismo ocurre en las dos siguientes secciones, que son las dedicadas a las cuestiones histórico-artísticas. La segunda está dedicada al patrimonio arquitectónico de la fundación, abordando el estudio del templo primigenio -consistente en la unificación de varias viviendas colindantes en la calle San Jerónimo- y de la posterior Iglesia de los Dolores, proyectada por el arquitecto Melchor de Aguirre. Cabe aquí destacar el extenso y minucioso análisis de la arquitectura del segundo oratorio, tratando cada una de sus partes en diferentes apartados ilustrados con dibujos y fotografías de gran calidad. No obstante, aparte de tratar su fábrica original, Díaz Gómez documenta la evolución del edificio a lo largo de los siglos XIX y XX, pasando por las exclaustraciones, la invasión francesa y la llegada de los misioneros redentoristas, explicándose así el aspecto del actual Santuario del Perpetuo Socorro. Finalmente, la última sección hace referencia al patrimonio mueble del Oratorio, donde aparecen escultores tan significativos como José de Mora, Agustín de Vera Moreno o Torcuato Ruiz del Peral, y pintores como Juan de Sevilla o Pedro Atanasio de Bocanegra. Con todo ello, el autor deja constancia del importante patrocinio artístico de dicha congregación, así como logra poner en valor el valioso patrimonio artístico que perteneció al entonces Oratorio.

En definitiva, José Antonio Díaz Gómez descubre al lector la historia que se esconde detrás del actual Santuario de Nuestra Señora del Perpetuo Socorro de Granada, antiguo Oratorio de San Felipe Neri, un templo que, aparte de convertirse en un referente del Barroco tardío en Andalucía, fue testigo de la trascendencia histórica y patrimonial de una fundación perseguida. 